\title{
A specific exercise strategy reduced the need for surgery in subacromial pain patients
}

\author{
Hanna Björnsson Hallgren, Theresa Holmgren, Birgitta Öberg, Kajsa Johansson and Lars \\ Adolfsson
}

\section{Linköping University Post Print}

\section{Tweet}

N.B.: When citing this work, cite the original article.

Original Publication:

Hanna Björnsson Hallgren, Theresa Holmgren, Birgitta Öberg, Kajsa Johansson and Lars Adolfsson, A specific exercise strategy reduced the need for surgery in subacromial pain patients, 2014, British Journal of Sports Medicine, (48), 1431-1436.

http://dx.doi.org/10.1136/bjsports-2013-093233

Copyright: BMJ Publishing Group

http://group.bmj.com/

Postprint available at: Linköping University Electronic Press

http://urn.kb.se/resolve?urn=urn:nbn:se:liu:diva-111441 


\section{Title page}

Title: A specific exercise strategy reduced the need of surgery in subacromial pain patients.

Authors: Hanna C. Björnsson Hallgren $\mathrm{PhD}^{\mathrm{a}}$, Theresa Holmgren $\mathrm{PhD}^{\mathrm{b}}$, Birgitta Öberg Professor $^{\mathrm{b}}$, Kajsa Johansson $\mathrm{PhD}^{\mathrm{b}}$, Lars E. Adolfsson Professor ${ }^{\mathrm{a}}$

${ }^{a}$ Department of Orthopaedics, University Hospital of Linköping, Institution for Clinical and Experimental Medicine, Linköping University, SE-581 83, Linköping, Sweden

${ }^{\mathrm{b}}$ Institution of Medical and Health Sciences, Division of Physiotherapy, Linköping University, SE-581 83, Linköping, Sweden

Corresponding author: Hanna C. Björnsson Hallgren

Address: Department of Orthopaedics, University Hospital of Linköping, SE-581 85, Linköping, Sweden

Telephone number: +46709473276

Fax number: +46 101034305

E-mail: hanna.bjornsson.hallgren@lio.se

Keywords: Shoulder injuries, Physiotherapy, Eccentric exercise, Tendon, Ultrasounds 


\begin{abstract}
Background and purpose: A program based on eccentric exercises, for treating subacromial pain was in a previous study found effective at 3-month follow-up. The purposes of the present study were to investigate if the results were maintained after 1 year and if baseline Constant-Murley score, rotator cuff status and radiological findings influenced outcome. Patients and methods: 97 patients on the waiting list for arthroscopic subacromial decompression had been randomised to a specific exercise program or unspecific exercises (controls). After 3 months of exercises the patients were asked if they still wanted surgery and this option was available until a 1-year follow-up. One year after inclusion or 1 year after surgery, the number of patients that decided to have surgery in each group was compared. The choice of surgery was related to the baseline Constant-Murley score, ultrasound and radiographs taken at inclusion.
\end{abstract}

Results: All patients had improved significantly $(\mathrm{p}<0.0001)$ in Constant-Murley score at the 1-year follow-up. Significantly more patients in the control group decided to have surgery $(63 \%)$ than in the specific exercise group $(24 \%)(\mathrm{p}<0.0001)$. Patients that decided to have surgery had a significantly lower baseline Constant-Murley score and more often a fullthickness tear. Patients with partial tears did not differ from those with intact tendons. Interpretation: The positive short-term results of specific exercises were maintained after 1 year, and this exercise strategy reduces the need for surgery. Full-thickness tear and low baseline Constant-Murley score appear to be a predictive marker for a less good outcome. 


\section{What are the new findings?}

- Specific exercises reduced the need of surgery for subacromial pain

- Results are maintained after 1 year

- Patients with a full-thickness rotator cuff tear and a low baseline Constant-Murley score are prone to choose surgery.

\section{How might it impact on clinical practice in the near future?}

- Specific exercises should be first line of treatment for subacromial pain

- Less subacromial pain patients require surgery

- Specific exercises aids in selecting patients that require surgery for subacromial pain

- Patients unsatisfied after specific exercises may reach satisfactory result after surgery 


\section{Introduction}

Subacromial pain is common and may cause disability as well as negatively influence quality of life. ${ }^{1,2}$ Since the etiology appears multifactorial, involving several anatomical structures, the choice of treatment is challenging. ${ }^{1}$ Initial treatment is usually physiotherapy and corticosteroid injections. ${ }^{2}$ The role of exercise treatment has been investigated in several studies but evidence for efficacy is still limited and there is no consensus on the ideal program. ${ }^{3-6}$ When exercise treatment fails, surgical intervention with arthroscopic subacromial decompression (ASD) ${ }^{7}$ is recommended. Despite that equivalent effects of physiotherapy and ASD has been reported, ${ }^{8-10}$ the number of operations have continued to increase. $^{11}$

Rotator cuff tears may be associated with subacromial pain and the optimal management is uncertain. ${ }^{1,12}$ The reported success rate of exercise treatment in patients with full-thickness tears varies from $33 \%$ to $88 \% .^{4,13}$ This variability could be due to different inclusion criteria, treatment and evaluation methods, stressing the need for search of factors influencing treatment response. ${ }^{4,13}$ We have previously reported successful short-term results after a specific exercise program with focus on eccentric exercises used for patients on waiting list for surgery due to subacromial pain. ${ }^{14}$ Despite that all patients had undergone previous physiotherapy, the majority decided to decline surgery after 3 months of the specific exercises. The purposes of the present study were to examine if these positive short-term results were maintained after 1 year and if baseline Constant-Murley (C-M) score, rotator cuff status and radiologic findings influenced the decision about surgery.

\section{Material and Methods}

\section{Patient enrolment}

Ninety-seven patients, 36 women and 61 men with a mean age of 52 years (30-65), had been randomised to a specific exercise program or a control exercise program. All patients had 
clinical signs of subacromial pain but not of a major cuff tear. The study group was recruited from the waiting list for ASD at a University Hospital in Sweden. The indication for ASD was more than 6 months durations of pain despite conservative treatment and no clinical signs of major cuff dysfunction. The inclusion criteria were: lateral shoulder pain at rest or during arm elevation; at least 6 months with the current symptoms (table I), and an unsatisfactory results after at least 3 months of shoulder exercises in primary care. Furthermore, 3 of the following 4 criteria had to be positive: Impingement Sign according to Neer; ${ }^{15}$ or HawkinsKennedy; ${ }^{16}$ Jobes Test $;{ }^{17}$ or Patte Test. ${ }^{18}$ A positive Neer's impingement test (subacromial injection of local anesthetic ${ }^{19}$ was also compulsory. Exclusion criteria were: significant loss of flexion, abduction or strength in rotation indicating a major cuff tear; malignancy; osteoarthritis of the glenohumeral or acromioclavicular joints; previous fracture or surgery of the shoulder-girdle; os acromiale; polyarthritis; fibro-myalgia; instability in any shoulder joint; frozen shoulder; cervical pain; subacromial corticosteroid injection during the last 3 months and inability to understand written and spoken Swedish. According to the Hospital Anxiety and/or Depression Scale (HAD) ${ }^{20}$, used as a screening tool at baseline, no patients showed any mental distress. All patients gave their written consent after verbal and written information. The study was approved by the regional committee for medical ethics in Linköping (dnr: M124-07).

\section{Interventions}

Figure 1 shows an overview of the study design. The included patients had been randomised to either of the 2 exercise programs, blinded to if their program was considered the most effective. The specific program: included eccentric exercises for the rotator cuff and a combination of concentric and eccentric exercises for scapula stabilisers, all with progression of load. The patients were recommended to load with pain up to a subjectively assessed 5 on a 0-10 scale according to a pain-monitoring model. ${ }^{21}$ The exercises utilised by the control group included 6 active movements for the neck and shoulder without any load or progression. 
These were: shoulder abduction, retraction and elevation, neck retraction and stretch of upper trapezius and pectoralis major muscles. The exercises were instructed to be pain free. The programs have previously been described in detail. ${ }^{14}$ At inclusion all patients had received a subacromial corticosteroid injection (1 mL Triamcinolon $20 \mathrm{mg} / \mathrm{mL}$ mixed with $6 \mathrm{~mL}$ mepivacain $10 \mathrm{mg} / \mathrm{mL}$ ). Within 2 weeks a physiotherpist introduced the allocated exercises and gave standardised information about the shoulder condition and ergonomics. Visits at the physiotherapist were weekly for both groups the first 2 weeks and then every other week over the following 10 weeks (a total of 7 visits). The patients recorded adherence of home exercise sessions in a diary. After 3 months, at a visit to a blinded, shoulder surgeon, all patients were asked if they still wanted surgery and, if so, were operated on within 3 months. The option of surgery was then continuously available until the 1-year follow-up. Surgery included arthroscopic inspection of the glenohumeral joint and subacromial space, bursal and acromial resection (ASD) as described by Ellman. ${ }^{7}$ One of 2 experienced senior shoulder surgeons, not involved in the study, performed all surgical procedures. Postoperatively all patients performed a previously described 3-month exercise program routinely used after ASD, supervised by a physiotherapist. ${ }^{22}$

\section{Outcome measures and assessments}

Radiographic examination had been performed at inclusion using anterior-posterior, lateral, axillary and acromioclavicular views. An experienced radiologist and a shoulder surgeon, independently assessed the radiographs for osteoarthritis in the gleno-humeral or acromioclavicular joints, proximal humeral migration, subacromial calcification and subacromial degeneration. Subacromial degeneration was considered present with 1 or more of the following findings; sclerosis, cysts and spur formations on the greater humeral tuberosity and/or under the acromion. Findings of subacromial degeneration were dichotomised into 2 categories: yes ( 1 or more signs) and no (0 signs). After inclusion a 
bilateral shoulder ultrasound was performed by an experienced radiologist and repeated independently by a shoulder surgeon. The equipment used was a Siemens Acuson Sequoia 512 (Acuson, Mountain View, CA, USA) with a variable 8-10 MHz linear array-transducer. The extension of a cuff tear was categorised as total or subtotal referring to the width of the affected tendon and depth assessed as a partial thickness tear (PTT) or full thickness tear (FTT). ${ }^{23}$ Tear size was not measured in mm. PTT was defined as a localised absence of the tendon seen in 2 orthogonal planes as a mixed hyper- and hypoechogenic region. FTT was defined as a non-visualisation of the tendon throughout the entire thickness. ${ }^{23}$ The patients were kept blinded to their ultrasound findings until the final follow-up.

Inter-assessor agreement was calculated for radiological and sonographic assessments. All score measurements was conducted by the same, blinded shoulder surgeon at inclusion, after 3 months and 1 year after the repective treatments (figure 1).

Primary outcomes were the C-M score ${ }^{24}$ and number of operated patients. Secondary outcomes were: Disability of the Arm, Shoulder and Hand questionnaire (DASH) Score 25,26 (Swedish version), visual analogue scale $(\mathrm{VAS})^{27}(0-100 \mathrm{~mm})$ to assess pain intensity at rest, during arm activity and at night, health- related quality-of-life (HQRL) using the EuroQol Instrument (EQ-5D and EQ VAS) ${ }^{28}$ All instruments are validated or recommended. ${ }^{29}$

\section{Sample size}

A power analysis based on the C-M score ${ }^{24}$ was calculated for the initial study ${ }^{14}$ and showed that 82 patients would be required to detect a mean 10-point group difference with a variability of 16 points $(\beta=0.80,2$-sided $\alpha=0.05){ }^{3,9,14}$ To compensate for dropouts, a further 20 patients were recruited.

\section{Randomisation}

Fifty-five numbers of each treatment alternative were concealed in opaque envelopes, mixed and numbered by an independent physiotherapist. Patients were coded consecutively at 
inclusion by the surgeon and treatment allocation according to the draw of the envelope was decided at the first visit to the physiotherapist. The randomisation procedure has previously been described in detail. ${ }^{14}$

\section{Statistical analysis}

Parametric and non-parametric tests were used for comparison of baseline variables. For within-group comparisons paired T-test was used to calculate differences in total scores between 3 months and 1 year. The number of patients choosing surgery in each group was compared using Pearson's $\chi^{2}$ test. For proportions of radiologic and ultrasound findings Fisher's Exact test was used. Inter-assessor agreement on imaging findings was graded as very good, good, moderate, fair or poor using the kappa-value according to Altman. ${ }^{30}$ Associations between imaging findings, baseline C-M score, and the patient's choice of surgery (yes/no) were analysed with logistic regressions. In the logistic regression analysis the C-M score at baseline was divided into quartiles (0-35, 36-44, 45-58 and 59-100 points) and gender was adjusted for. $\mathrm{P}<0.05$ was considered significant. The statistical software package StataCorp LP, College Station, Texas 77845, USA was used.

\section{Results}

\section{Adherence and baseline data}

Ninety-five patients were assessed at 1-year follow-up. Two patients of the included 97, 1 in each group, did not attend the 1-year follow-up due to non-shoulder related disease (figure 1). All included patients had, prior to inclusion, undergone at least 3 monts of physiotherapistassisted shoulder exercises in primary care. No patients had received structured eccentric exercises and the intensity and monitoring varied. Eighty-five of the 95 patients had received or several subacromial corticosteroid injections more than 3 months before inclusion. There was no significant difference in the number of injections between the treatment groups. Both 
groups had similar adherence to exercises and physiotherapist appointments. The groups were comparable at baseline except more male patients in the specific exercise group (table I). 
Table I. Background variables for the 2 groups according to randomisation. Values are numbers with percentages in brackets unless stated otherwise.

\begin{tabular}{|c|c|c|}
\hline & $\begin{array}{c}\text { Specific exercises } \\
(n=51)\end{array}$ & $\begin{array}{c}\text { Control exercises } \\
(n=46)\end{array}$ \\
\hline Male & $37 *$ & 24 \\
\hline Age (y) mean (range) & $52(33-65)$ & $52(37-65)$ \\
\hline $\begin{array}{l}\text { Duration of pain (months) } \\
\text { median (range) } \\
\text { Dominant side affected } \\
\text { Affected shoulder (right:left) }\end{array}$ & $\begin{array}{c}24(6-120) \\
30(59) \\
32: 18\end{array}$ & $\begin{array}{c}12(6-156) \\
22(48) \\
22: 24\end{array}$ \\
\hline \multicolumn{3}{|l|}{ Occupation } \\
\hline Heavy load & $22(43)$ & $21(46)$ \\
\hline Light load & $29(57)$ & $25(55)$ \\
\hline On sick leave at start & $9(18)$ & $9(20)$ \\
\hline \multicolumn{3}{|l|}{ Rotator cuff status } \\
\hline Intact & $33(65)$ & $34(74)$ \\
\hline Partial tear & $15(29)$ & $6(13)$ \\
\hline Full thickness & $3(6)$ & $6(13)$ \\
\hline \multicolumn{3}{|l|}{ Radiology } \\
\hline Subacromial calcification & $9(18)$ & $11(24)$ \\
\hline Subacromial degeneration & $7(14)$ & $9(18)$ \\
\hline \multicolumn{3}{|l|}{$\operatorname{HAD}^{\mathrm{a}}(0-21)$} \\
\hline Anxiety, mean (range) & $3.3(0-12)$ & $3.9(0-13)$ \\
\hline Depression, mean (range) & $2.2(0-9)$ & $2.5(0-12)$ \\
\hline
\end{tabular}

*Statistically significant more men in the specific exercise group $(\mathrm{p}=0.04)$. PTT=partial-

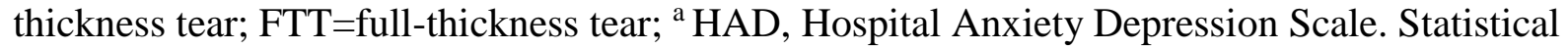
level of significance $\mathrm{p}<0.05$.

\section{1-year assessment}

The C-M score had continued to improve significantly between 3 months and 1 year $(\mathrm{p}<$ 0.0001) (table II, figure 2) as well as all the secondary outcomes $(\mathrm{p}<0.05)$ (table III).

Significantly more patients in the control group had decided to have surgery (63\%) compared to the specific exercise group $(24 \%)(\mathrm{p}<0.0001)$ (table II, figure 1). 
Table II. Mean (SD) values in Constant-Murley score, the original 2 groups at baseline and 3-month follow-up and the 4 groups that appeared after the patients' decision about surgery at 3-month or 1-year follow-up. Time dependent changes of score values are illustrated in figure 2 .

\begin{tabular}{|c|c|c|c|c|c|}
\hline Groups & $\begin{array}{l}\text { Baseline } \\
\text { C-M score }^{\mathrm{a}}\end{array}$ & $\begin{array}{l}\text { 3-month } \\
\text { C-M score }\end{array}$ & Groups & $\begin{array}{l}\text { 3-month } \\
\text { C-M score }\end{array}$ & $\begin{array}{l}\text { 1-year } \\
\text { C-M score }\end{array}$ \\
\hline \multirow[t]{2}{*}{ Specific } & \multirow[t]{2}{*}{$\begin{array}{l}48(15) \\
(n=51)\end{array}$} & \multirow[t]{2}{*}{$\begin{array}{l}72(19) \\
(n=51)\end{array}$} & $\begin{array}{l}\text { Specific } \\
\text { Non-surgery }\end{array}$ & $\begin{array}{l}78(13) \\
(n=41)\end{array}$ & $\begin{array}{l}84(14)^{b} \\
(n=38)\end{array}$ \\
\hline & & & $\begin{array}{l}\text { Specific } \\
\text { Surgery }\end{array}$ & $\begin{array}{l}53(22) \\
(\mathrm{n}=10)\end{array}$ & $\begin{array}{l}79(12) \\
(n=12)\end{array}$ \\
\hline \multirow[t]{2}{*}{ Control } & \multirow[t]{2}{*}{$\begin{array}{l}43(15) \\
(n=46)\end{array}$} & \multirow[t]{2}{*}{$\begin{array}{l}52(23) \\
(n=46)\end{array}$} & $\begin{array}{l}\text { Control } \\
\text { Non-surgery }\end{array}$ & $\begin{array}{l}75(14) \\
(n=17)\end{array}$ & $\begin{array}{l}85(13)^{b} \\
(n=16)\end{array}$ \\
\hline & & & $\begin{array}{l}\text { Control } \\
\text { Surgery }\end{array}$ & $\begin{array}{l}40(16) \\
(n=29)\end{array}$ & $\begin{array}{l}72(18) \\
(n=29)\end{array}$ \\
\hline
\end{tabular}

${ }^{\mathrm{a}} \mathrm{C}-\mathrm{M}$ score $=$ Constant-Murley score 0-100 (100 = maximum shoulder function $)$.

${ }^{\mathrm{b}}$ In the period from 3-month to 1-year follow-up 1 patient was lost in the specific non-surgery group and in the control non-surgery group due to non shoulder-related disease. 
Table III. Mean (SD) values in all outcomes at baseline, 3-month and 1-year follow-ups for the 2 originally randomised groups and the groups that appeared after the patients' decision about surgery at 3-month or 1-year follow-up.

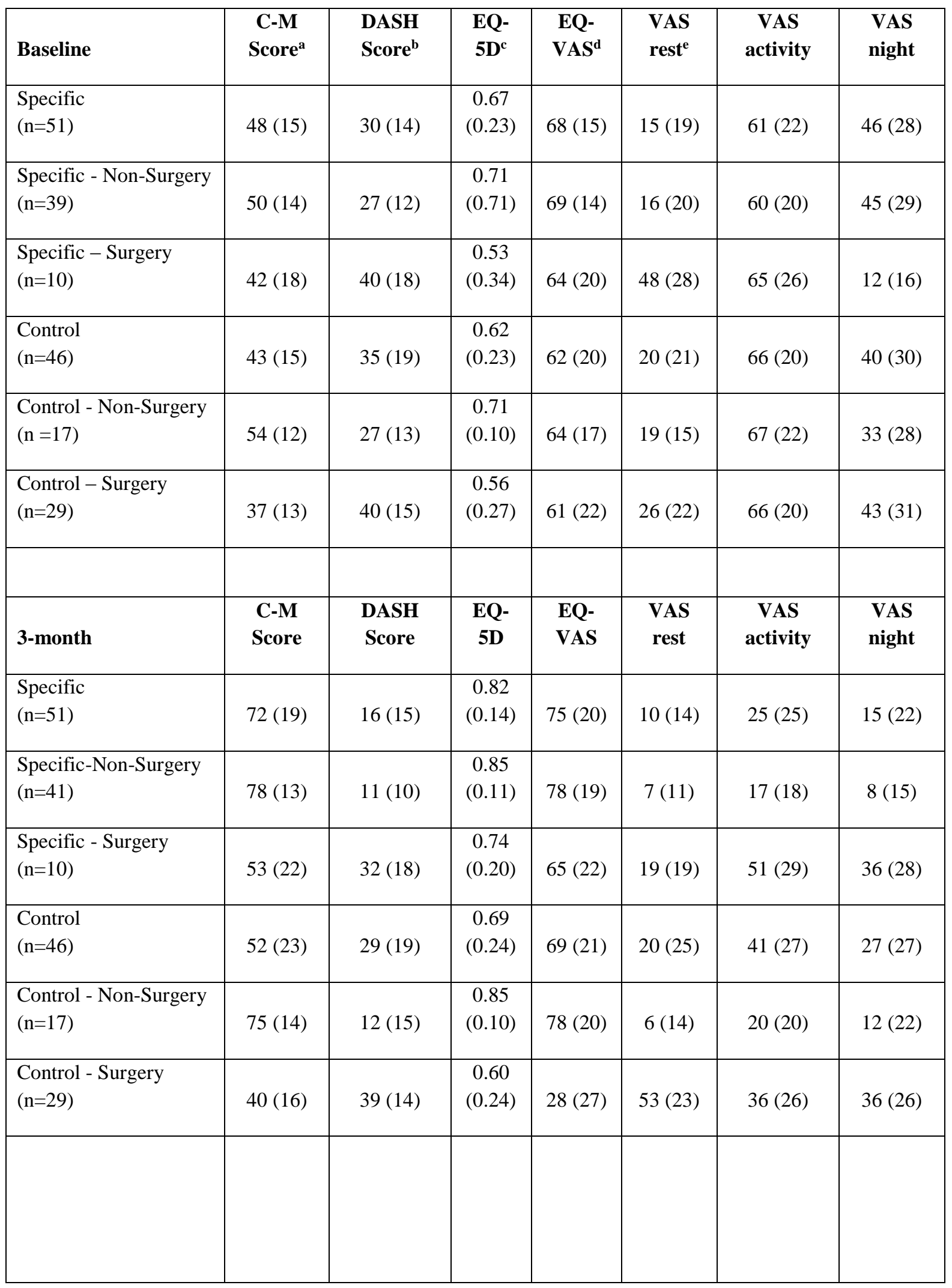




\begin{tabular}{|l|c|c|c|c|c|c|c|}
\hline 1-year & $\begin{array}{c}\text { C-M } \\
\text { Score }\end{array}$ & $\begin{array}{c}\text { DASH } \\
\text { Score }\end{array}$ & $\begin{array}{c}\text { EQ- } \\
\text { 5D }\end{array}$ & $\begin{array}{c}\text { EQ- } \\
\text { VAS }\end{array}$ & $\begin{array}{c}\text { VAS } \\
\text { rest }\end{array}$ & $\begin{array}{c}\text { VAS } \\
\text { activity }\end{array}$ & $\begin{array}{c}\text { VAS } \\
\text { night }\end{array}$ \\
\hline $\begin{array}{l}\text { Specific } \\
(\mathrm{n}=50)^{*}\end{array}$ & $83(14)$ & $9(11)$ & $\begin{array}{c}0.88 \\
(0.11)\end{array}$ & $84(14)$ & $2(6)$ & $18(23)$ & $12(19)$ \\
\hline $\begin{array}{l}\text { Specific - Non-Surgery } \\
(\mathrm{n}=38)\end{array}$ & $84(14)$ & $7(9)$ & $\begin{array}{c}0.90 \\
(0.11)\end{array}$ & $87(11)$ & $2(7)$ & $15(22)$ & $11(18)$ \\
\hline $\begin{array}{l}\text { Specific - Surgery } \\
(\mathrm{n}=12)\end{array}$ & $79(12)$ & $16(13)$ & $\begin{array}{c}0.81 \\
(0.09)\end{array}$ & $76(19)$ & $0.8(3)$ & $28(24)$ & $15(23)$ \\
\hline $\begin{array}{l}\text { Control } \\
(\mathrm{n}=45)^{*}\end{array}$ & $76(18)$ & $13(15)$ & $\begin{array}{c}0.86 \\
(0.15)\end{array}$ & $78(19)$ & $4(13)$ & $18(21)$ & $14(21)$ \\
\hline $\begin{array}{l}\text { Control - Non-Surgery } \\
(\mathrm{n}=16)\end{array}$ & $85(13)$ & $5(6)$ & $\begin{array}{c}0.90 \\
(0.11)\end{array}$ & $86(13)$ & $5(16)$ & $12(18)$ & $11(19)$ \\
\hline $\begin{array}{l}\text { Control - Surgery } \\
(\mathrm{n}=29)\end{array}$ & $72(18)$ & $18(16)$ & $\begin{array}{c}0.83 \\
(0.17)\end{array}$ & $73(20)$ & $4(11)$ & $21(23)$ & $15(22)$ \\
\hline
\end{tabular}

${ }^{\mathrm{a}} \mathrm{C}-\mathrm{M}$ score $=$ Constant-Murley score 0-100 $(100=$ maximum shoulder function $)$.

${ }^{\mathrm{b}}$ DASH score=Disabilities of the Arm Shoulder and Hand score 0-100 in which 0 is the best shoulder function

${ }^{\mathrm{c}}$ EQ-5D index 1- (-0.59) in which -0.59 is the lowest health-related quality of life.

${ }^{\mathrm{d}}$ EQ-VAS (0-100) in which 0 is the lowest health status.

${ }^{\mathrm{e}}$ Pain VAS (Visual Analogue Scale) 0-100 $\mathrm{mm}$ in which 100 is the worst imaginable pain.

*One patient lost between baseline and 3-month follow-up.

Two patients, in the specific exercise group, decided to have surgery between the 3-month and 1-year visits due to recurrent symptoms (figure 1). The mean C-M score for all patients was 80 (SD 16) at the 1-year follow-up. Patients from both intervention groups not wanting surgery, had a mean C-M score of 84 (SD 14) and patients that had undergone surgery a mean of 74 (SD 17) 1 year after surgery.

At the 1-year follow-up 5 patients in the specific exercise group and 4 in the control group reported that they had continued with their exercises for another 2 months. Inter-assessor agreement between the investigators was very good ${ }^{30}$ for both radiology and ultrasound. 
Differing ultrasound assessments occurred in five cases where the radiologist's opinion was used (table V).

Table IVa. Radiological assessments of 97 patients with subacromial pain by the 2 investigators. The Findings of subacromial degeneration (table IVa) and calcification (table IVb) were dichotomised into 2 categories: yes ( 1 or more signs) and no ( 0 signs).

\begin{tabular}{|l|c|c|}
\hline Subacromial degeneration & \multicolumn{2}{|c|}{${\text { Investigator } \mathrm{B}^{\mathrm{b}}}^{\mid 2}$} \\
\hline Investigator $\mathrm{A}^{\mathrm{a}}$ & Yes & No \\
\hline Yes & 16 & 81 \\
\hline No & 0 & 0 \\
\hline
\end{tabular}

Table IVb.

\begin{tabular}{|l|c|c|}
\hline Subacromial calcification & \multicolumn{2}{|c|}{ Investigator B } \\
\hline Investigator A ${ }^{\mathrm{a}}$ & Yes & No \\
\hline Yes & 20 & 0 \\
\hline No & 0 & 77 \\
\hline
\end{tabular}

${ }^{\mathrm{a}}$ Investigator $\mathrm{A}=$ The most experienced shoulder surgeon assessing the radiographs

${ }^{\mathrm{b}}$ Investigator $\mathrm{B}=$ Experienced radiologist 
Table V. Ultrasound assessments of the rotator cuff of 97 patients with subacromial pain by the 2 investigators. The rotator cuff was categorised into intact, partial-thickness and fullthickness tearing.

\begin{tabular}{|l|c|c|c|}
\hline Ultrasound finding & \multicolumn{3}{|c|}{ Investigator $\mathrm{B}^{\mathrm{b}}$} \\
\hline Investigator $\mathrm{A}^{\mathrm{a}}$ & Intact & PTT & FTT \\
\hline Intact & 63 & 0 & 1 \\
\hline PTT & 4 & 21 & 8 \\
\hline FTT & 0 & 0 & 0 \\
\hline
\end{tabular}

${ }^{\mathrm{a}}$ Investigator $\mathrm{A}=$ Shoulder surgeon

${ }^{\mathrm{b}}$ Investigator $\mathrm{B}=$ Experienced radiologist

Intact $=$ no cuff tearing, PTT $=$ partial-thickness tear, FTT $=$ full-thickness tear

Thirty of the 97 included patients had cuff tears (table I). There was no significant difference in tear type between the 2 groups. Twenty-six patients had isolated supraspinatus tears and 4 had a combination of lesions involving supraspinatus, subscapularis and the long head of biceps. Twenty-one of the single tendon tears were PTT and were FTTs. Four patients with FTTs involving both supraspinatus and subscapularis decided to have surgery.

A significantly larger proportion of patients with radiographic signs of subacromial degeneration had a FTT $(\mathrm{p}=0.03)$. The presence of subacromial calcification or degeneration did not independently influence the choice of surgery. Patients with a baseline C-M score in the lower quartile had a significantly larger risk of choosing surgery, independently of gender, treatment group and rotator cuff status compared to the highest quartile, odds ratio 7.7 (95\% CI 1.67 to 33.3) and $\mathrm{p}=0.007$ (table VI). Patients in the control group treated non-operatively had the highest mean C-M score 54 (SD 12) at baseline. Gender and decision of surgery were not statistically related. In the retrospective correlation of baseline data and outcome, the 
overall improvement in C-M score was $44(88 \%)$ in the specific non-surgery group, 37 (88\%) in the specific surgery group, $31(57 \%)$ in the control non-surgery group and $35(95 \%)$ in the control surgery group.

Table VI. The baseline Constant-Murley score divided into quartiles. The number of patients in each quartile and the number of patients who decided surgery.

\begin{tabular}{|l|l|l|}
\hline C-M score $^{\text {a }}$ quartiles (baseline) & $\mathbf{n}$ & Surgery (n) \\
\hline $0-35$ & 25 & 17 \\
\hline $36-44$ & 24 & 12 \\
\hline $45-58$ & 24 & 7 \\
\hline $59-100$ & 22 & 5 \\
\hline
\end{tabular}

${ }^{\mathrm{a}} \mathrm{C}-\mathrm{M}$ score $=$ Constant-Murley score 0-100 $(100=$ maximum shoulder function $)$

A FTT significantly increased the risk, odds ratio 5.5, for choosing surgery compared to patients with intact tendons. No increased risk was found associated with a PTT (table VII).

Table VII. The influence of rotator cuff status in relation to the patient's choice of surgery (yes/no) during the follow-up period analysed with logistic regression. The reference group was patients with intact rotator cuff.

\begin{tabular}{|l|l|l|l|l|}
\hline $\mathbf{n}$ & $\begin{array}{l}\text { Rotator } \\
\text { cuff } \\
\text { status }\end{array}$ & $\begin{array}{l}\text { Odds } \\
\text { Ratio }\end{array}$ & $\begin{array}{l}\mathbf{9 5 \%} \\
\text { Confidence } \\
\text { interval }\end{array}$ & p-value \\
\hline 67 & Intact & 1 & - & - \\
\hline 21 & PTT & 1 & 0.4 to 2.7 & 0.95 \\
\hline 9 & FTT & 5.5 & 1.1 to 28.6 & 0.04 \\
\hline
\end{tabular}

PTT $=$ partial-thickness tear, FTT $=$ full-thickness tear

Statistical level of significance $\mathrm{p}<0.05$. 


\section{Discussion}

This study demonstrates that, in a 1-year perspective, most patients with subacromial pain of relatively long duration can be treated successfully without surgery. Especially the specific exercise program used in the current study allowed improvement of shoulder function to the extent that surgery could be avoided. The components of the specific exercise program that differ from current practice are the eccentric focus, acceptance of pain during loading and load progression guided by pain assessment. The contribution of each part of the program can however not be elucidated with the used study design. Eccentric exercises for subacromial pain have previously only been evaluated in pilot studies ${ }^{31,32}$ but efficacy is reported after treatment of other tendinoses. ${ }^{33}$ The effect mechanism of eccentric exercises is not fully understood but several theories have been presented. ${ }^{34-37}$

In the present study moderate pain was allowed during load in accordance with other programs for eccentric exercises ${ }^{38,39}$ which might have contributed to the positive effect. Baseline characteristics of patients with shoulder pain have been suggested as the most important predictor of outcome in primary care. ${ }^{40}$ This corresponds to our finding that patients with the lowest baseline C-M score significantly more often decided to have surgery. It has been reported that patients with FTT have less favourable results after physiotherapy ${ }^{13}$, ${ }^{41}$ as well as after ASD. ${ }^{42,43}$ Moosmayer et al. ${ }^{44}$ compared cuff repair and physiotherapy for small and medium sized tears and found better outcome for the surgery group. However, 82 $\%$ of their non-operated patients reported satisfactory results. ${ }^{44} \mathrm{We}$ found that patients with FTT to a larger extent decided to have surgery compared to patients with intact tendons and PTT. Four of the 9 patients with FTT had 2 tendons affected and they all decided on surgery, indicating that the extent of the lesion might influence the response to exercises. Since major cuff dysfunction was a criterion for exclusion no patients with massive tears or tears involving infraspinatus were included. The 4 diagnosed FTTs of the subscapularis tendon 
were in all cases subtotal, caused therefore no marked reduction of strength and were consequently not diagnosed by clinical examination. Due to the limited number of patients with FTTs any correlation between structural lesions and outcome should be interpreted with caution.

A recent study, evaluating criteria for successful outcome after ASD, found that radiological signs of subacromial degeneration was indicative for a successful outcome. ${ }^{45}$ In the present study a significant association was found between subacromial degeneration and a FTT. This association was expected since these findings are considered to be involved in the same degenerative process. ${ }^{42,46}$ The presence of subacromial degeneration did however not independently influence the choice of surgery, which tallies with previous reports. ${ }^{47}$ All patientes, regardless of treatment, had improved in all outcome measurements between 3 months and 1 year, and on a group level the improvements were statistically significant. The final outcome was superior for the specific group in which significantly fewer decided to have surgery. These findings demonstrate that the specific program is not only preferable but may also serve as a screening tool to select candidates for surgery.

The responsiveness to exercises is probably multifactorial; including psychological, physiological and biomechanical properties, structural tissue changes and the capability of developing compensatory mechanisms. ${ }^{48}$ Natural course, adaptation and increased attention being a study participant, may further add to a favourable outcome in all groups. Considering the strict inclusion criteria, long duration, excellent adherence and initial randomisation in the present study, it however appears unlikely that natural course and psychological influence could explain the significant group differences.

The corticosteroid injections given at inclusion are likely to have had an initial pain-reducing effect $^{49}$ and were administred in order to facilitate the start-up of physiotherapy. ${ }^{50}$ Due to the relatively short duration of an injection effect, ${ }^{49}$ it is less probable that this would have had an 
impact on the course between 3 months and 1 year. Similarly, the initial physiotherapist guidance may have contributed to early positive effects but would not account for group differences after 3 months. ${ }^{51}$

In interpreting the results some methodological aspects should be considered. The present study primarily addresses the course between 3 months and 1 year after treatment and is consequently observational, although based on an initailly randomised study. Therefore, when assessing the retrospective analysis of the baseline data, the fact that 2 patients were lost to follow-up and that 2 other had moved between treatment groups must be taken into account. Another concern is the single non-blinded care provider. This avoids inter-personal differences in attitudes and skills but might affect validity. It may be argued that the positive effect of the specific exercises could be attributed to a dedicated physiotherapist that unintentionally influenced the patients' perception of their treatment, as well as choosing surgery or not. We are aware of this risk but believe that since all included patients were given the same information and had previously performed exercises, it seems less probable that this explains group difference.

One year is a relatively short follow-up period but in the light of previous reports describing early results after both ASD and physiotherapy for subacromial pain to be reliable in long term, ${ }^{8,10,52}$ we believe that our results will be long lasting.

Our findings are in line with previous reports, finding exercise treatment for subacromial pain to be as efficient as surgery. ${ }^{8-10,53}$ Compared to other studies investigating efficacy of eccentric exercises the present study rendered even better outcome in favour of the specific program with higher number of withdrawals from surgery. ${ }^{31,32}$

\section{Conclusions}

The positive short-term outcomes after our specific exercise program were maintained and even further improved until the 1-year follow-up, reducing the need of surgery significantly 
more than unspecific control exercises. Based on these results we recommend that all patients with subacromial pain, without clinical signs of major cuff tears, should initially be treated with 3-months of specific exercises. The severity of shoulder disability at baseline and the presence of a full-thickness tear seem to influence outcome and the need of surgery. 


\section{References}

1. Seitz AL, McClure PW, Finucane S, et al. Mechanisms of rotator cuff tendinopathy: intrinsic, extrinsic, or both? Clin Biomech (Bristol, Avon) 2011;26:1-12.

2. Johansson K, Oberg B, Adolfsson L, et al. A combination of systematic review and clinicians' beliefs in interventions for subacromial pain. Br J Gen Pract 2002;52:145-52.

3. Kelly SM, Wrightson PA, Meads CA. Clinical outcomes of exercise in the management of subacromial impingement syndrome: a systematic review. Clin Rehabil 2010;24:99-109.

4. Ainsworth R, Lewis JS. Exercise therapy for the conservative management of full thickness tears of the rotator cuff: a systematic review. Br J Sports Med 2007;41:200-10.

5. Kromer TO, Tautenhahn UG, de Bie RA, et al. Effects of physiotherapy in patients with shoulder impingement syndrome: a systematic review of the literature. J Rehabil Med 2009;41:870-80.

6. Hanratty CE, McVeigh JG, Kerr DP, et al. The Effectiveness of Physiotherapy Exercises in Subacromial Impingement Syndrome: A Systematic Review and Meta-Analysis. Semin Arthritis Rheum 2012.

7. Ellman H. Arthroscopic subacromial decompression: analysis of one- to three-year results. Arthroscopy 1987;3:173-81.

8. Haahr JP, Andersen JH. Exercises may be as efficient as subacromial decompression in patients with subacromial stage II impingement: 4-8-years' follow-up in a prospective, randomized study. Scand J Rheumatol 2006;35:224-8.

9. Ketola S, Lehtinen J, Arnala I, et al. Does arthroscopic acromioplasty provide any additional value in the treatment of shoulder impingement syndrome?: a two-year randomised controlled trial. J Bone Joint Surg Br 2009;91:1326-34.

10. Brox JI, Gjengedal E, Uppheim G, et al. Arthroscopic surgery versus supervised exercises in patients with rotator cuff disease (stage II impingement syndrome): a prospective, 
randomized, controlled study in 125 patients with a 2 1/2-year follow-up. J Shoulder Elbow Surg 1999;8:102-11.

11. Swedish board of health database of statistics, updated yearly between 2005-10.

http://www.socialstyrelsen.se/statistik/statistikdatabas

12. Rees JL. The pathogenesis and surgical treatment of tears of the rotator cuff. J Bone Joint Surg Br 2008;90:827-32.

13. Tanaka M, Itoi E, Sato K, et al. Factors related to successful outcome of conservative treatment for rotator cuff tears. Ups J Med Sci 2010;115:193-200.

14. Holmgren T, Bjornsson Hallgren H, Oberg B, et al. Effect of specific exercise strategy on need for surgery in patients with subacromial impingement syndrome: randomised controlled study. BMJ 2012;344:e787.

15. Neer CS, 2nd. Anterior acromioplasty for the chronic impingement syndrome in the shoulder: a preliminary report. J Bone Joint Surg Am 1972;54:41-50.

16. Hawkins RJ, Kennedy JC. Impingement syndrome in athletes. Am J Sports Med 1980;8:151-8.

17. Jobe FW, Jobe CM. Painful athletic injuries of the shoulder. Clin Orthop Relat Res 1983:117-24.

18. Leroux JL, Thomas E, Bonnel F, et al. Diagnostic value of clinical tests for shoulder impingement syndrome. Rev Rhum Engl Ed 1995;62:423-8.

19. Neer CS, 2nd, Welsh RP. The shoulder in sports. Orthop Clin North Am 1977;8:583-91. 20. Zigmond AS, Snaith RP. The hospital anxiety and depression scale. Acta Psychiatr Scand 1983;67:361-70.

21. Thomee R. A comprehensive treatment approach for patellofemoral pain syndrome in young women. Phys Ther 1997;77:1690-703. 
22. Holmgren T, Oberg B, Sjoberg I, et al. Supervised strengthening exercises versus homebased movement exercises after arthroscopic acromioplasty: A randomized clinical trial. $J$ Rehabil Med 2011.

23. Bjornsson HC, Norlin R, Johansson K, et al. The influence of age, delay of repair, and tendon involvement in acute rotator cuff tears: structural and clinical outcomes after repair of 42 shoulders. Acta Orthop 2011;82:187-92.

24. Constant CR, Murley AH. A clinical method of functional assessment of the shoulder. Clin Orthop Relat Res 1987:160-4.

25. Atroshi I, Gummesson C, Andersson B, et al. The disabilities of the arm, shoulder and hand (DASH) outcome questionnaire: reliability and validity of the Swedish version evaluated in 176 patients. Acta Orthop Scand 2000;71:613-8.

26. Hudak PL, Amadio PC, Bombardier C. Development of an upper extremity outcome measure: the DASH (disabilities of the arm, shoulder and hand) [corrected]. The Upper Extremity Collaborative Group (UECG). Am J Ind Med 1996;29:602-8.

27. Carlsson AM. Assessment of chronic pain. I. Aspects of the reliability and validity of the visual analogue scale. Pain 1983;16:87-101.

28. Rabin R, de Charro F. EQ-5D: a measure of health status from the EuroQol Group. Ann Med 2001;33:337-43.

29. Constant CR, Gerber C, Emery RJ, et al. A review of the Constant score: modifications and guidelines for its use. J Shoulder Elbow Surg 2008;17:355-61.

30. Altman DG. Inter-rater agreement. Practical Statistics for Medical Research. London: Chapman \& Hall; 1991. p. 403-9.

31. Jonsson P, Wahlstrom P, Ohberg L, et al. Eccentric training in chronic painful impingement syndrome of the shoulder: results of a pilot study. Knee Surg Sports Traumatol Arthrosc 2006;14:76-81. 
32. Bernhardsson S, Klintberg IH, Wendt GK. Evaluation of an exercise concept focusing on eccentric strength training of the rotator cuff for patients with subacromial impingement syndrome. Clin Rehabil 2011;25:69-78.

33. Magnussen RA, Dunn WR, Thomson AB. Nonoperative treatment of midportion Achilles tendinopathy: a systematic review. Clin J Sport Med 2009;19:54-64.

34. Rees JD, Wolman RL, Wilson A. Eccentric exercises; why do they work, what are the problems and how can we improve them? Br J Sports Med 2009;43:242-6.

35. Stanish WD, Rubinovich RM, Curwin S. Eccentric exercise in chronic tendinitis. Clin Orthop Relat Res 1986:65-8.

36. Brughelli M, Cronin J. Influence of running velocity on vertical, leg and joint stiffness : modelling and recommendations for future research. Sports Med 2008;38:647-57.

37. Langberg H, Ellingsgaard H, Madsen T, et al. Eccentric rehabilitation exercise increases peritendinous type I collagen synthesis in humans with Achilles tendinosis. Scand J Med Sci Sports 2007;17:61-6.

38. Purdam CR, Jonsson P, Alfredson H, et al. A pilot study of the eccentric decline squat in the management of painful chronic patellar tendinopathy. Br J Sports Med 2004;38:395-7. 39. Lewis JS. Rotator cuff tendinopathy: a model for the continuum of pathology and related management. Br J Sports Med 2010;44:918-23.

40. Thomas E, van der Windt DA, Hay EM, et al. Two pragmatic trials of treatment for shoulder disorders in primary care: generalisability, course, and prognostic indicators. Ann Rheum Dis 2005;64:1056-61.

41. Kim HM, Teefey SA, Zelig A, et al. Shoulder strength in asymptomatic individuals with intact compared with torn rotator cuffs. J Bone Joint Surg Am 2009;91:289-96. 
42. Benson RT, McDonnell SM, Rees JL, et al. The morphological and immunocytochemical features of impingement syndrome and partial-thickness rotator-cuff tear in relation to outcome after subacromial decompression. J Bone Joint Surg Br 2009;91:119-23.

43. Bjornsson H, Norlin R, Knutsson A, et al. Fewer rotator cuff tears fifteen years after arthroscopic subacromial decompression. J Shoulder Elbow Surg 2010;19:111-5.

44. Moosmayer S, Lund G, Seljom U, et al. Comparison between surgery and physiotherapy in the treatment of small and medium-sized tears of the rotator cuff: A randomised controlled study of 103 patients with one-year follow-up. J Bone Joint Surg Br 2010;92:83-91.

45. Magaji SA, Singh HP, Pandey RK. Arthroscopic subacromial decompression is effective in selected patients with shoulder impingement syndrome. J Bone Joint Surg Br 2012;94:1086-9.

46. Ozaki J, Fujimoto S, Nakagawa Y, et al. Tears of the rotator cuff of the shoulder associated with pathological changes in the acromion. A study in cadavera. J Bone Joint Surg Am 1988;70:1224-30.

47. Hamid N, Omid R, Yamaguchi K, et al. Relationship of radiographic acromial characteristics and rotator cuff disease: a prospective investigation of clinical, radiographic, and sonographic findings. J Shoulder Elbow Surg 2012;21:1289-98.

48. Lentz TA, Barabas JA, Day T, et al. The relationship of pain intensity, physical impairment, and pain-related fear to function in patients with shoulder pathology. J Orthop Sports Phys Ther 2009;39:270-7.

49. Dogu B, Yucel SD, Sag SY, et al. Blind or ultrasound-guided corticosteroid injections and short-term response in subacromial impingement syndrome: a randomized, double-blind, prospective study. American journal of physical medicine \& rehabilitation / Association of Academic Physiatrists 2012;91:658-65. 
50. Crawshaw DP, Helliwell PS, Hensor EM, et al. Exercise therapy after corticosteroid injection for moderate to severe shoulder pain: large pragmatic randomised trial. $B M J$ 2010;340:c3037.

51. Thorstensson CA, Roos EM, Petersson IF, et al. How do middle-aged patients conceive exercise as a form of treatment for knee osteoarthritis? Disabil Rehabil 2006;28:51-9.

52. Lunsjo K, Bengtsson M, Nordqvist A, et al. Patients with shoulder impingement remain satisfied 6 years after arthroscopic subacromial decompression: a prospective study of 46 patients. Acta Orthop 2011;82:711-3.

53. Coghlan JA, Buchbinder R, Green S, et al. Surgery for rotator cuff disease. Cochrane Database Syst Rev 2008:3. 
Acknowledgement: We thank Mats Fredriksson, statistician at the Linköping University for help with the statistical analyses.

Competing interests: There is no financial interest or other relationships that may lead to a conflict of interest concerning this paper.

Funding: The study was funded by the Linköping University Hospital, but no other support, financial or other, was received for this study and none financial biases exists for any of the authors or their immediate family.

Contributor ship statement: $\mathrm{HB}, \mathrm{TH}, \mathrm{BÖ}, \mathrm{KJ}$ and LA conceived and designed the study protocol. TH and KJ designed the physiotherapy interventions. HB did the statistical analyses with assistance from a statistician employed at the department of medical and health sciences. HB was the blinded assessor. HB drafted the manuscript, and TH, BÖ, KJ and LA contributed to the manuscript. All authors read and approved the final manuscript. LA is guarantor.

Trial registration: Clinical trials $\underline{\text { NCT01037673 }}$

\section{Figure legends}

1. Flow chart according to consolidated standards of reporting trials (CONSORT-statement) with the number of of patients randomised, adherent and choosing surgery during the followup period.

2. The mean Constant-Murley score in the two original groups at baseline and three-month assessment. The three-month and one-year mean Constant-Murley score in the four groups divided by the choice of surgery. Constant-Murley score 0-100 $(100=$ maximum shoulder function). * One year after completion of exercises (non-surgery group) and one year after surgery. Mean values and standard deviation are written out in Table II. 